\title{
Light extraction efficiency enhancement of flip-chip blue light-emitting diodes by anodic aluminum oxide
}

\author{
Yi-Ru Huang ${ }^{1}$, Yao-Ching Chiu ${ }^{2}$, Kuan-Chieh Huang ${ }^{3}$, Shao-Ying Ting ${ }^{3}$, Po-Jui Chiang ${ }^{4}$, \\ Chih-Ming Lai ${ }^{5}$, Chun-Ping Jen ${ }^{6}$, Snow H. Tseng ${ }^{1}$ and Hsiang-Chen Wang ${ }^{*}$
}

\author{
Full Research Paper \\ Address: \\ ${ }^{1}$ Graduate Institute of Photonics and Optoelectronics, National \\ Taiwan University, No. 1, Sec. 4, Roosevelt Rd., Taipei 10617, \\ Taiwan, ${ }^{2}$ Graduate Institute of Opto-Mechatronics, National Chung \\ Cheng University, 168 University Rd., Min-Hsiung, Chia-Yi 62102, \\ Taiwan, ${ }^{3}$ R\&D Center, Genesis Photonics Inc., No.5, Dali 3rd Rd., \\ Shanhua Dist., Tainan City 74144 , Taiwan, ${ }^{4}$ Department of Electronic \\ Engineering, National Kaohsiung University of Applied Sciences, \\ No.415, Jiangong Rd., Sanmin Dist., Kaohsiung City 80778, Taiwan, \\ ${ }^{5}$ Department of Electronic Engineering, Ming Chuan University, \\ Taoyuan 333, Taiwan, and ${ }^{6}$ Department of Mechanical Engineering, \\ National Chung Cheng University, 168 University Rd., Min-Hsiung, \\ Chia-Yi 62102, Taiwan \\ Email: \\ Hsiang-Chen Wang ${ }^{*}$ - hcwang@ccu.edu.tw \\ * Corresponding author \\ Keywords: \\ anodic aluminum oxide; critical angle of total reflection; efficiency \\ enhancement; flip-chip blue light-emitting diode \\ Beilstein J. Nanotechnol. 2018, 9, 1602-1612. \\ doi:10.3762/bjnano.9.152 \\ Received: 26 January 2018 \\ Accepted: 27 April 2018 \\ Published: 30 May 2018 \\ Associate Editor: A. J. Meixner \\ (C) 2018 Huang et al.; licensee Beilstein-Institut. \\ License and terms: see end of document.
}

\begin{abstract}
We produced an anodic aluminum oxide (AAO) structure with periodic nanopores on the surface of flip-chip blue light-emitting diodes (FC-BLEDs). The nanopores had diameters ranging from 73 to $85 \mathrm{~nm}$ and were separated by distances ranging from approximately 10 to $15 \mathrm{~nm}$. The light extraction efficiency enhancement of the FC-BLEDs subjected to different durations of the second pore-widening process was approximately $1.6-2.9 \%$. The efficiency enhancement may be attributed to the following mechanism: periodic nanopores on the surface of FC-BLEDs reduce the critical angle of total reflection and effective energy transfer from a light emitter into a surface plasmon mode produced by AAO.
\end{abstract}

\section{Introduction}

Light-emitting diodes (LEDs) are widely used in various fields, such as optical communication and automobile lighting [1-6]. The luminous efficiency of LEDs is defined as follows [7]. The luminous intensity of a $280 \mathrm{~nm}$ periodic structure in blue light and under a driving current of $700 \mathrm{~mA}$ is approximately $728.3 \mathrm{~mW}$ and is approximately $180 \mathrm{~lm} / \mathrm{W}$ in white light [8,9]. Improving the luminous efficiency of LEDs is difficult. Ryu et al. prepared a scattering layer composed of fine inorganic parti- 
cles. They then sprayed a planarization layer composed of acrylic acid resin or polyimide resin on the scattering layer and obtained a LED surface with high flatness and hardness; these properties enhanced the light extraction efficiency (LEE) of the LED [10]. Ding et al. fabricated a LED with enhanced LEE by depositing a patterned sapphire substrate (PSS) on a flip-chip LED with GaN as a base layer [11]. Shei et al. enhanced the LEE of LEDs by $27 \%$ by producing a microstructure on the surface of LEDs with Ga-doped zinc oxide (GZO)/GaN as the base layer and then reducing the total reflectivity by changing the shape, thickness, and density of the microstructure through dry etching [12]. Li et al. increased the LEE of an InGaN-monolayer quantum-well LED by 1.8-1.9 times relative to that of a traditional LED by producing a $\mathrm{TiO}_{2}$ microstructure array on p-GaN through dipping and rapid convective deposition and using noncrystalline $\mathrm{TiO}_{2}$ and anatase $\mathrm{TiO}_{2}$ with a diameter of $520 \mathrm{~nm}$ [13]. Huang et al. used $\mathrm{Zn}$ and $\mathrm{Mg}$ for ion implantation at the GZO thin layer and then adopted rapid thermal annealing to enhance the LEE of short-wavelength purple and ultraviolet LEDs by 1.4-2.5 times that of a traditional LED [14]. Ryu et al. adopted anodic aluminum oxide (AAO) to produce a photonic crystal structure at the $\mathrm{n}-\mathrm{GaN}$ layer of LEDs, and transmission electron microscopy (TEM) images showed that screw dislocations in the LED structure were blocked, thus enhancing the general luminous efficiency by approximately $23 \%$ [15]. Cates et al. adopted laser etching to produce a repeated microstructure on the emitting surface of a yttrium aluminum perovskite scintillation crystal activated by cerium (formula $\mathrm{YAlO}_{3}$ : Ce, abbreviated as YAP:Ce) and reduced the total reflection of light via surface roughening. The LEE of the LED was approximately two times that of traditional LEDs [16]. The use of a high-index-contrast photonic crystal $[17,18]$ and colloidal-based microsphere arrays in conventional top-emitting LEDs [19], and microspheres and microlens arrays in thin-film flip-chip LEDs [20-22] and organic LEDs [23-25] has significantly improved the LEE. The use of microspheres and microlens arrays produced via the colloidal method has enabled the wafer-scale deposition of two-dimensional close-packed arrays with high density for GaN LEDs [19-22] and organic LEDs [23-25]. These technologies require multiple complicated processing methods or special materials and synthetic methods and are applied in LEDs with low luminous efficiency.

In the present study, AAO is used to produce a periodic nanostructures on high-luminance flip-chip blue LEDs (FC-BLEDs) to enhance the LEE [26,27]. This enhancement may occur through two mechanisms [28-34]. The nanostructure on the LED can decrease the total light reflectivity, thereby decreasing the critical angle of total reflectivity and enhancing LEE $[12,16,35,36]$. Whether the nanostructure, which possesses special metallic features, is influenced by the surface plasmon wave and enhances LEE has also been studied [37-40].

\section{Results and Discussion \\ Scanning electron microscopy and atomic force microscopy measurements}

The scanning electron microscopy (SEM) images of samples AAO60, AAO70, and AAO80 (whereby the numbers in the sample name indicate the duration of the pore-widening process, as described in the Experimental section) are shown in Figure 1a, Figure 1b, and Figure 1c, respectively. These figures show that the samples have a predominantly regular periodic nanostructure. The nanopore diameters of the three samples are approximately $73-75 \mathrm{~nm}, 77-79 \mathrm{~nm}$, and $80-85 \mathrm{~nm}$, and the distance between pores is approximately 15, 13, and $10 \mathrm{~nm} \pm 2 \mathrm{~nm}$. Figure 1a shows a relatively complete surface periodic structure; Figure 1b shows the presence of several fractures between pores, which are intensified; and Figure 1c shows a highly compromised structural integrity. The SEM results indicate that the pores gradually enlarge and that the distance between pores shortens as the duration of the second porewidening process is extended. When the duration of the porewidening process exceeds $70 \mathrm{~min}$, the surface structure is damaged. Surface destruction, in turn, affects the integrity of internal pores. AFM measurements were then performed to determine AAO thickness, pore depth, and pore consistency.
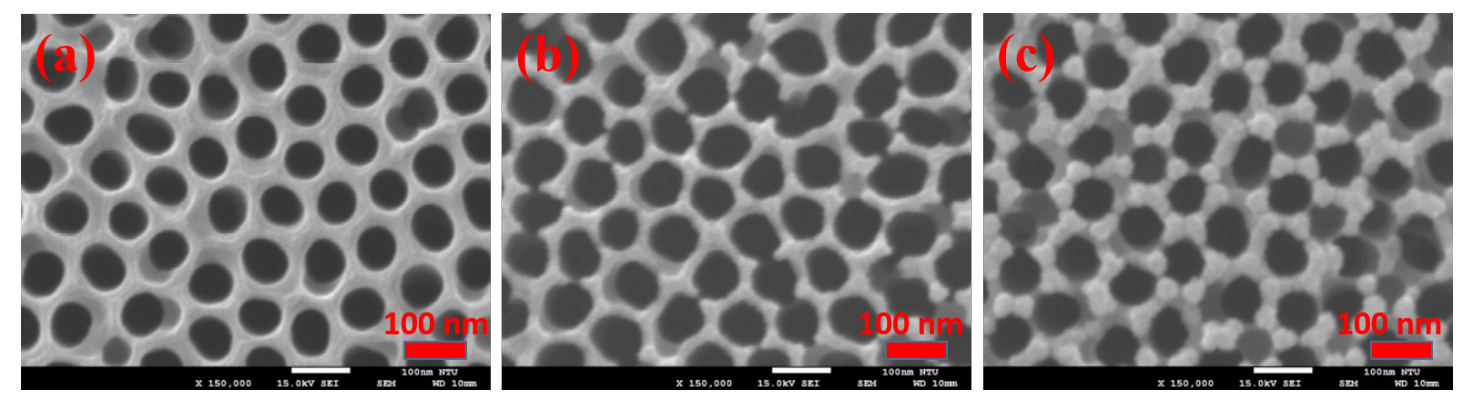

Figure 1: Scanning electron microscopy images of the anodic aluminum oxide (AAO) nanostructure on a sapphire substrate: sample (a) AAO60, (b) AAO70, and (c) AAO80. 
The AFM results of the three samples are shown in Figure 2. The results show the surface roughness and surface height distribution of the three samples. Figure 2a, Figure 2d, and Figure $2 \mathrm{~g}$ show the three-dimensional AFM images of AAO60, AAO70, and AAO80, respectively. Figure 2d shows the overall structure and structural integrity of the samples. The pores shown in Figure 2a have not widened completely, whereas those shown in Figure $2 \mathrm{~g}$ have widened excessively. Excessive widening destroys the surface structure. The AFM images of the three samples are shown in Figure 2b,e,h and were used to examine surface integrity, whereby pores are not evident in Figure $2 \mathrm{~b}$. Figure $2 \mathrm{~h}$ shows pores that have been etched excessively. Excessive etching destroys the surface structure. Figure $2 \mathrm{e}$ shows pores that have been completely etched. These results are consistent with the SEM measurements. We measured the line-scan profile of the AFM images to determine the correlation between the depth and width of the internal structure, as well as structural distribution. The results are shown in Figure 2c,f,i. AAO60 presents a surface depth difference of approximately $50 \pm 2 \mathrm{~nm}$, pore diameter of approximately $75 \pm 3 \mathrm{~nm}$, and the depth-to-width ratio of approximately 2:3 (see Figure 2c). The surface structure of AAO60 is uneven and complete. AAO70 presents the surface depth difference of approximately $100 \pm 3 \mathrm{~nm}$, pore diameter of approximately $78 \pm 3 \mathrm{~nm}$, and the depth-to-width ratio of approximately 4:3 (see Figure 2f). Moreover, an indistinct structure has been generated between $0-0.4 \mu \mathrm{m}$ of the $x$-axis (assuming that the sampling position is between the pores). Beyond $0.4 \mu \mathrm{m}$, the structural periodicity is extremely homogeneous and pore depth is consistent. AAO080 presents a surface depth difference of approximately $100 \pm 3 \mathrm{~nm}$, pore diameter of approximately $85 \pm 2 \mathrm{~nm}$, and a depth-to-width ratio of approximately 20:17. The depth distribution of pores is extremely homogenous (see Figure 2i). However, two neighboring pores $0.25 \mu \mathrm{m}$ from the measurement position are connected. Thus, destructive etching may occur on the surface. These results showed that as the dura-
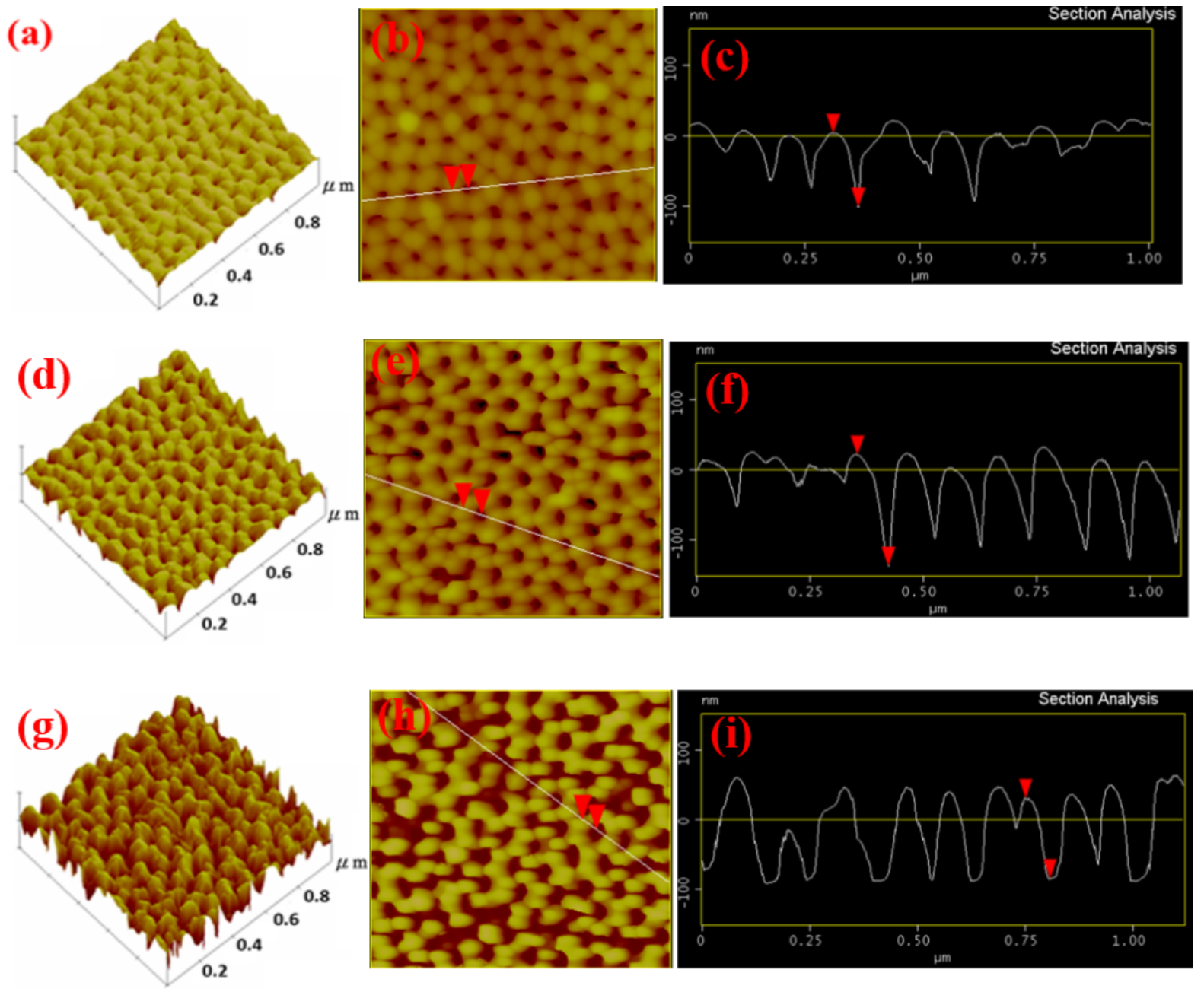

Figure 2: Atomic force microscopy measurements for samples (a-c) AAO60, (d-f) AAO70, and (g-i) AAO80. 
tion of the pore-widening process is extended, the diameter of AAO pores on the LED increases from $75 \mathrm{~nm}$ to $85 \mathrm{~nm}$, the surface depth increases from $50 \mathrm{~nm}$ to $100 \mathrm{~nm}$, and the depth-towidth ratio approaches $1: 1$. These effects result in surface destruction and pore connection. The above results indicate that AAO60 does not undergo inadequate etching. By contrast, AAO80 undergoes overetching, which causes surface destruction. Consistent with the SEM measurements, AAO70 exhibits the optimal pore periodicity.

\section{Transmission electron microscopy measure- ments}

To understand the internal structure and elemental distribution of the nanopores, the TEM images of the three samples were acquired. The images are shown in Figure 3, Figure 4, and Figure 5 . In these figures, the measurement scale is accurate in the $x$-direction, whereas in the $y$-direction, it is magnified to help identify the integrity of the pore structure in this direction. In Figure 3e, the orange dotted line represents the boundary between pores and the sapphire substrate of AAO60. The area bounded by the yellow dotted line is $\mathrm{Al}$, the area bounded by the blue dotted line is a pore, and the area between these lines is $\mathrm{Al}_{2} \mathrm{O}_{3}$. In Figure $3 \mathrm{a}$, most pores are etched completely and are connected to the sapphire substrate. Figure $3 \mathrm{~b}$ provides a magnified view of Figure $3 \mathrm{a}$ and shows the AAO pore structure in detail. In this figure, some pores are etched completely, while others are not. Figure $3 \mathrm{c}-\mathrm{e}$ shows the internal elemental distribution in individual pores. Figure $3 \mathrm{c}$ provides a magnified view of the single pore shown in Figure $3 \mathrm{~b}$. The detailed boundary of the pore is defined by dotted lines. Figure $3 \mathrm{~d}$ shows a magnified view of the region defined by the purple rectangle in
Figure 3c. The inset shows the diffraction pattern based on the fast Fourier transform of the green section in Figure 3d. The figure shows that the lattice structure is as regular as the hexagon lattice structure of Al. Figure 3e shows a magnified view of the red rectangle region shown in Figure 3c. This figure indicates that some pores have not been completely etched.

Figure 4a shows that most pores of AAO70 have been etched completely and are connected to the sapphire substrate. Moreover, the overall integrity of the pores is higher than that shown in Figure 3a. Figure 4b shows the TEM image of a higher rate. The pore integrity of AAO70 is superior to that of AAO60. Figure $4 \mathrm{c}$ and Figure $4 \mathrm{~d}$ are magnified views of the areas between the pores shown in Figure $4 \mathrm{a}$. Figure $4 \mathrm{e}$ is a magnified view of the red area in Figure $4 \mathrm{c}$ and shows that the pores are connected to the sapphire substrate. The three areas included an etched hole, Al, and the sapphire substrate. Figure $4 \mathrm{f}$ is a magnified view of the purple area shown in Figure 4d. The Al lattice structures are bounded by the yellow dotted line, with pores existing beyond the dotted line. Figure 5a shows that the pores of AAO80 have been etched completely and are connected to the sapphire substrate. However, most pores have been etched and destroyed internally, and their structures are not complete. Figure $5 \mathrm{~b}$ shows the AAO pore structure in detail. Figure $5 \mathrm{c}-\mathrm{e}$ shows the internal elemental distribution of individual pores. Figure $5 \mathrm{c}$ shows the structure between pores, and Figure $5 \mathrm{~d}$ is a magnified view of the purple area shown in Figure 5c. In Figure 5d, the area bounded by the yellow dotted line is Al. Figure 5e provides a magnified view of the red area shown in Figure 5c. The figure shows that the pores are connected with the substrate. We selected the green area in

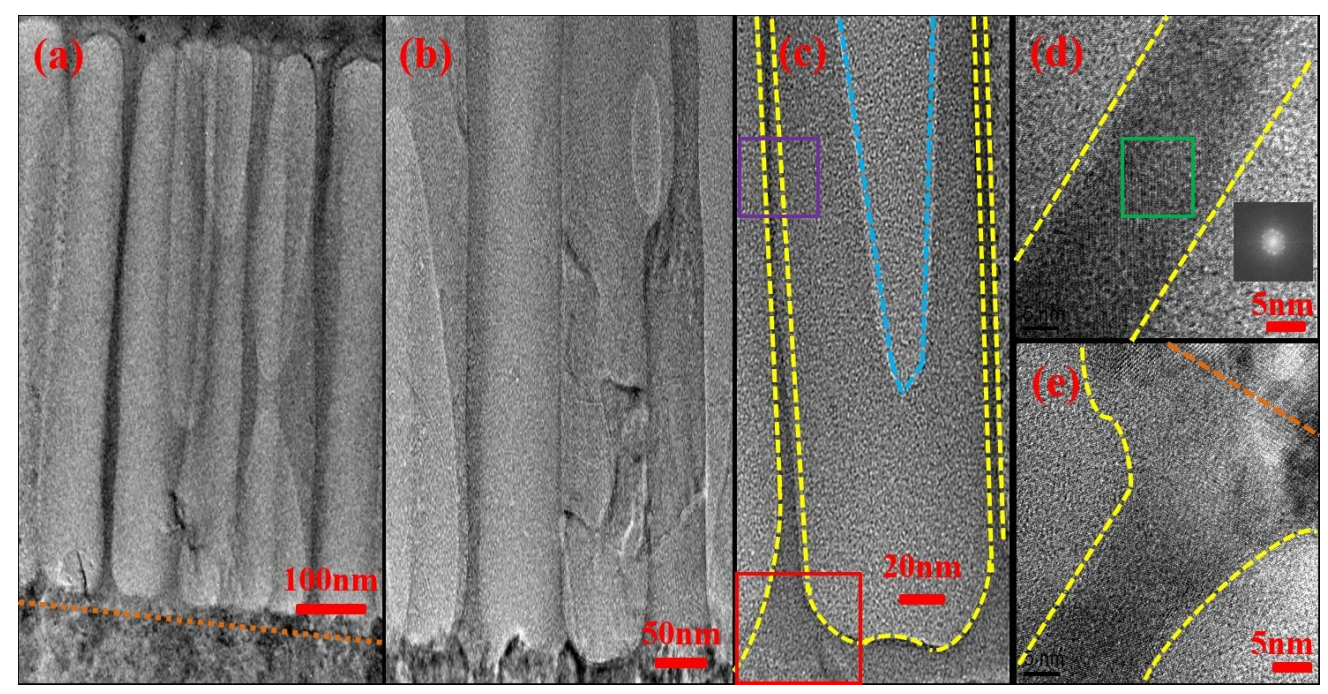

Figure 3: Transmission electron microscopy measurements for sample AAO60 at different magnifications: (a) complete pores exist at the sapphire substrate; (b) a magnified view of (a); (c) a magnified view of the single pore shown in (b); (d) a magnified view of the region defined by the purple rectangle in (c); and (e) a magnified view of the red rectangle region shown in (c). 


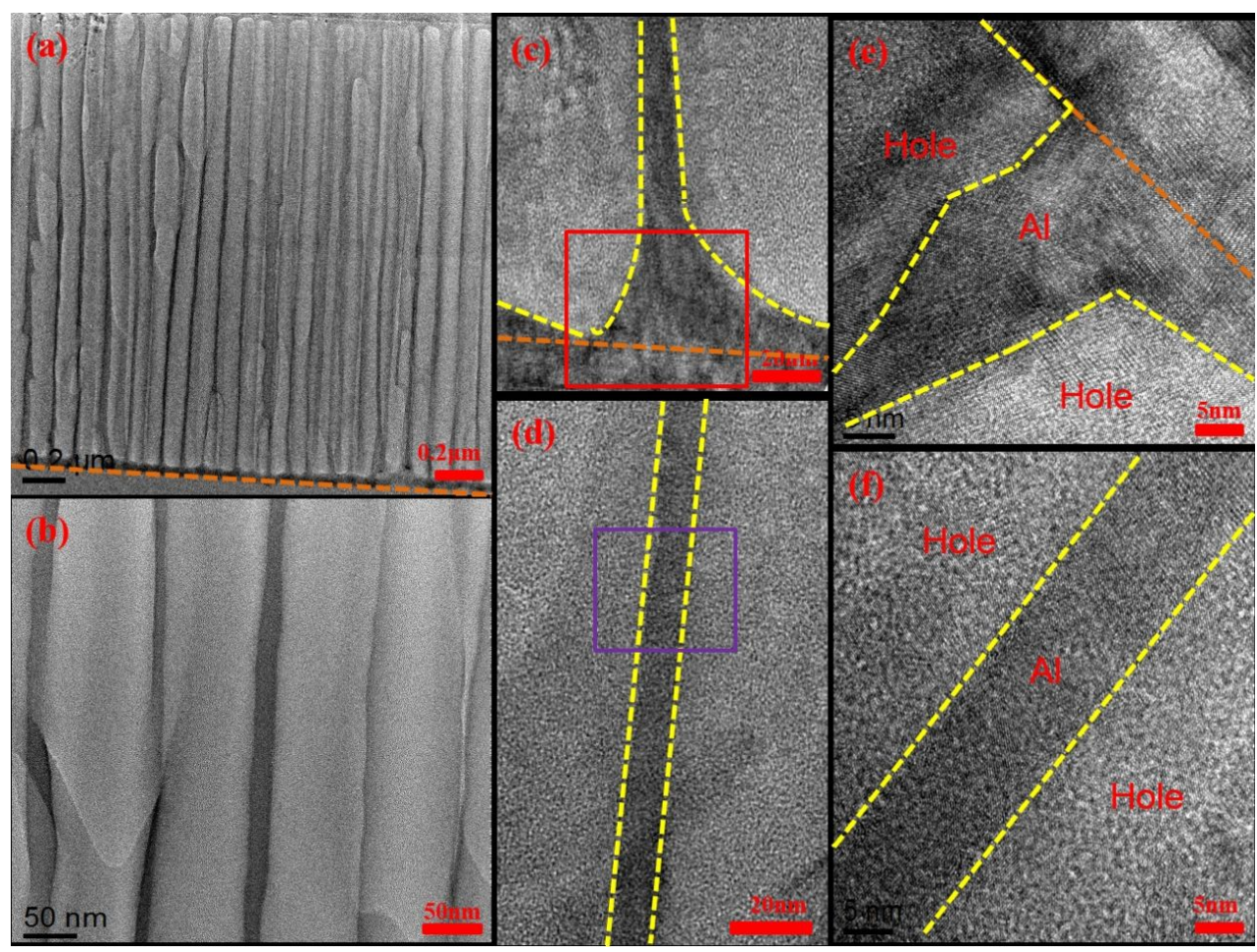

Figure 4: Transmission electron microscopy measurements for sample AAO70 obtained at different magnifications: (a) complete pores exist at the sapphire substrate; (b) a magnified view of (a); (c, d) magnified views of the areas between the pores shown in (a); (e) magnified view of the red area in (c); and (f) magnified view of the purple area shown in (d).

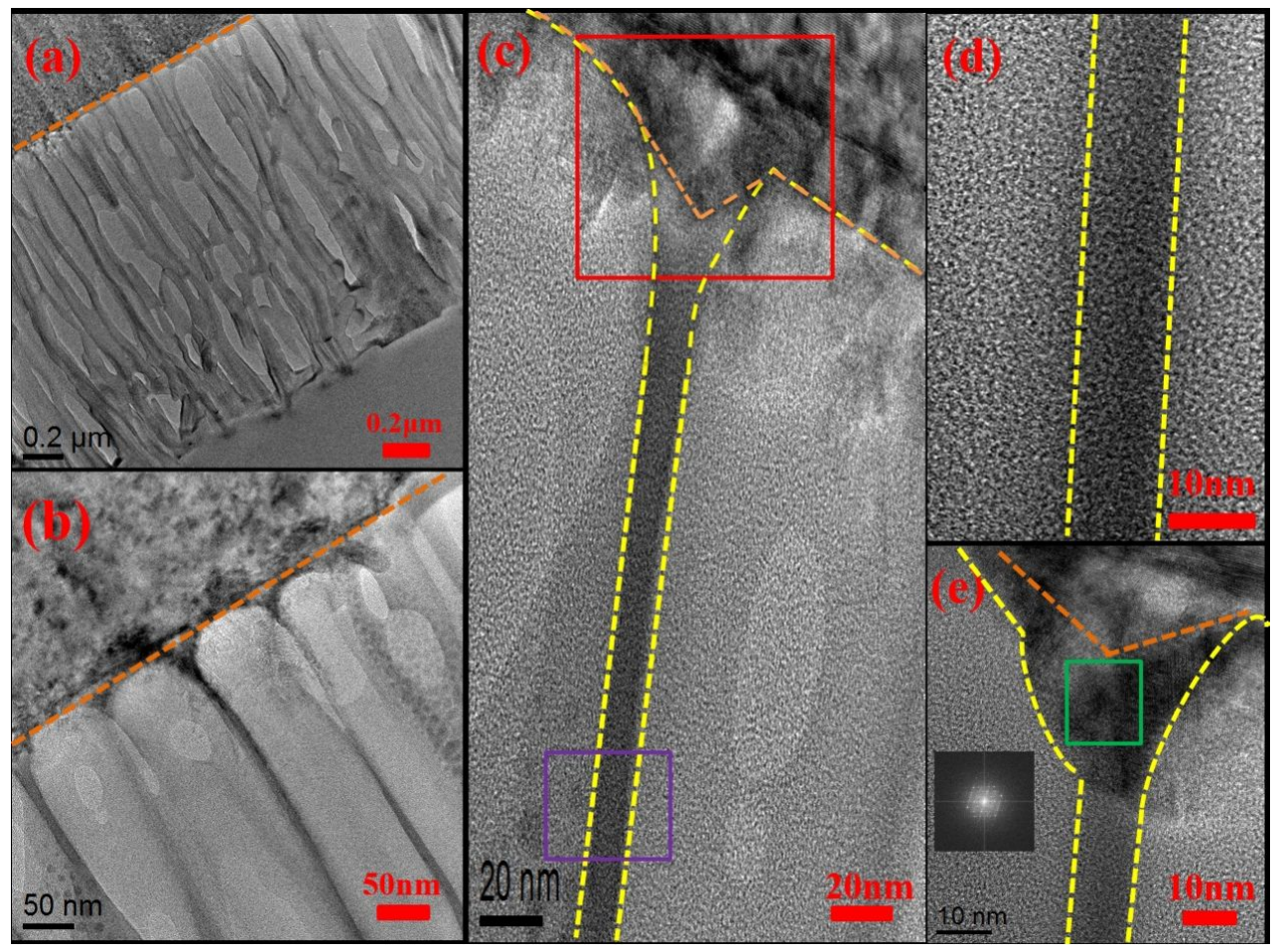

Figure 5: Transmission electron microscopy measurements for AAO80 obtained at different magnifications: (a) complete pores exist at the sapphire substrate; (b) magnified view of (a); (c) the structure between pores; (d) a magnified view of the purple area shown in (c); (e) a magnified view of the red area shown in (c). 
Figure $5 \mathrm{e}$ for lattice structure analysis. The results are shown as the inset figure in the image. The area bounded by the yellow dotted line and the orange dotted line at the bottom is a regular hexagonal lattice structure. TEM analysis results show that AAO70 has been completely but not excessively etched. By contrast, AAO60 has been incompletely etched, and AAO80 exhibits structural destruction caused by excessive etching. Thus, different pore-widening durations cause the pore integrity to vary among the samples. Excessive pore-widening duration can cause pore destruction, which influences LED luminous efficiency.

\section{Optical measurements}

Figure 6a shows the measured FC-BLED luminous wavelength and radiation angle of a structure-less crystal-covering type of LED, AAO60, AAO70, and AAO80. The LED with an AAO structure has higher luminous intensity than the LED without an AAO structure. The wavelength exhibits a blue shift of approximately $5 \mathrm{~nm}$. The following two mechanisms can explain the blue shift: First, InGaN multiquantum wells (MQWs) grow because of patterned sapphire substrate (PSS) technology and the luminous blue shift is generated by compressive strain release [26]. However, this study does not consider the contribution of this phenomenon. Second, the AAO process introduces the surface-plasmon-induced blue shift of LED emission between $\mathrm{Al}$ and the sapphire substrate [37,41-45]. Figure 6b shows that the luminous angle for the test block in AAO70 is the largest. The inadequate pore-widening duration of AAO60 results in inadequate pore etching, thereby influencing the surface luminous intensity and radiation angle of AAO60. The excessive pore-widening duration used to fabricate AAO80 causes the surface destruction of pores and thus resulted in the poor luminous intensity and small radiation angle of AAO80. Therefore, the optimal radiation angle and luminous intensity can be obtained with the pore-widening duration of $70 \mathrm{~min}$ (i.e., AAO70). To better understand the mechanisms underlying the blue shift of emission energy, the angle-resolved electroluminescence (AREL) spectra of the samples were collected and are shown in Figure 7a. The angular plots of all samples show broad protrusions between -50 to $50^{\circ}$. The electroluminescence (EL) intensity of AAO70 is approximately $2.9 \%$ higher than that of the bare FC-BLED. The AREL spectra of the samples are not significantly different. AREL results were calculated as follows:

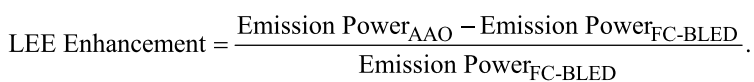

Figure $7 \mathrm{~b}-\mathrm{d}$ shows the angular resolution of the LEE enhancement of AAO60, AAO70, and AAO80. In Figure 7b-d, the LEE enhancement is negative at the angles of $50-60^{\circ}$ and energies of $455-480 \mathrm{~nm}$ given the blue shift of emission energy in the AAO-structured samples. Positive LEE enhancement values are obtained at angles of 55-90 and energies of $425-455 \mathrm{~nm}$. Figure $6 \mathrm{a}$ shows the same tendencies for these values. Figure $7 \mathrm{~b}$ shows that, consistent with the other optical measurements, AAO70 has the largest LEE enhancement values. The measurement results of AAO60, AAO70, and AAO80 are shown in Table 1. The number of test blocks is 30 . Extending the second pore-widening duration improves the efficiency enhancement. However, the luminous efficiency of AAO80 is inferior to that of AAO70 because the internal structure of the former has been destroyed. The results in Table 1 show that among all samples, AAO70 has the highest luminous rate, shortest luminous wavelength, and largest radiation angle. These improvements resulted from subjecting the LED surface to AAO. The light output power of the LED devices is measured using an integrating sphere system. Figure 8 shows the typical light output power-current-voltage $(L-I-V)$ characteristics of the LEDs with and without AAO structures. The AAO structures enhance the LEE of LEDs but do not change the $L-I-V$ properties.

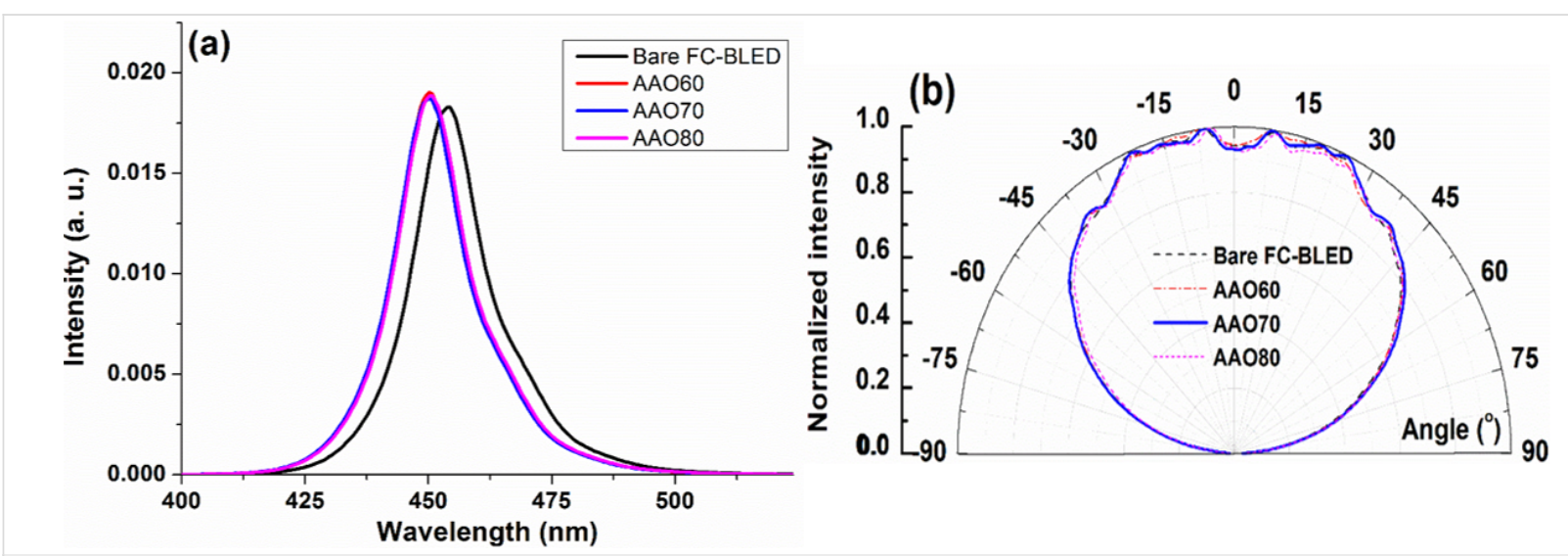

Figure 6: (a) Measured luminous wavelength versus energy and (b) luminous angle for samples AAO60, AAO70, AAO80, and bare FC-BLED. 

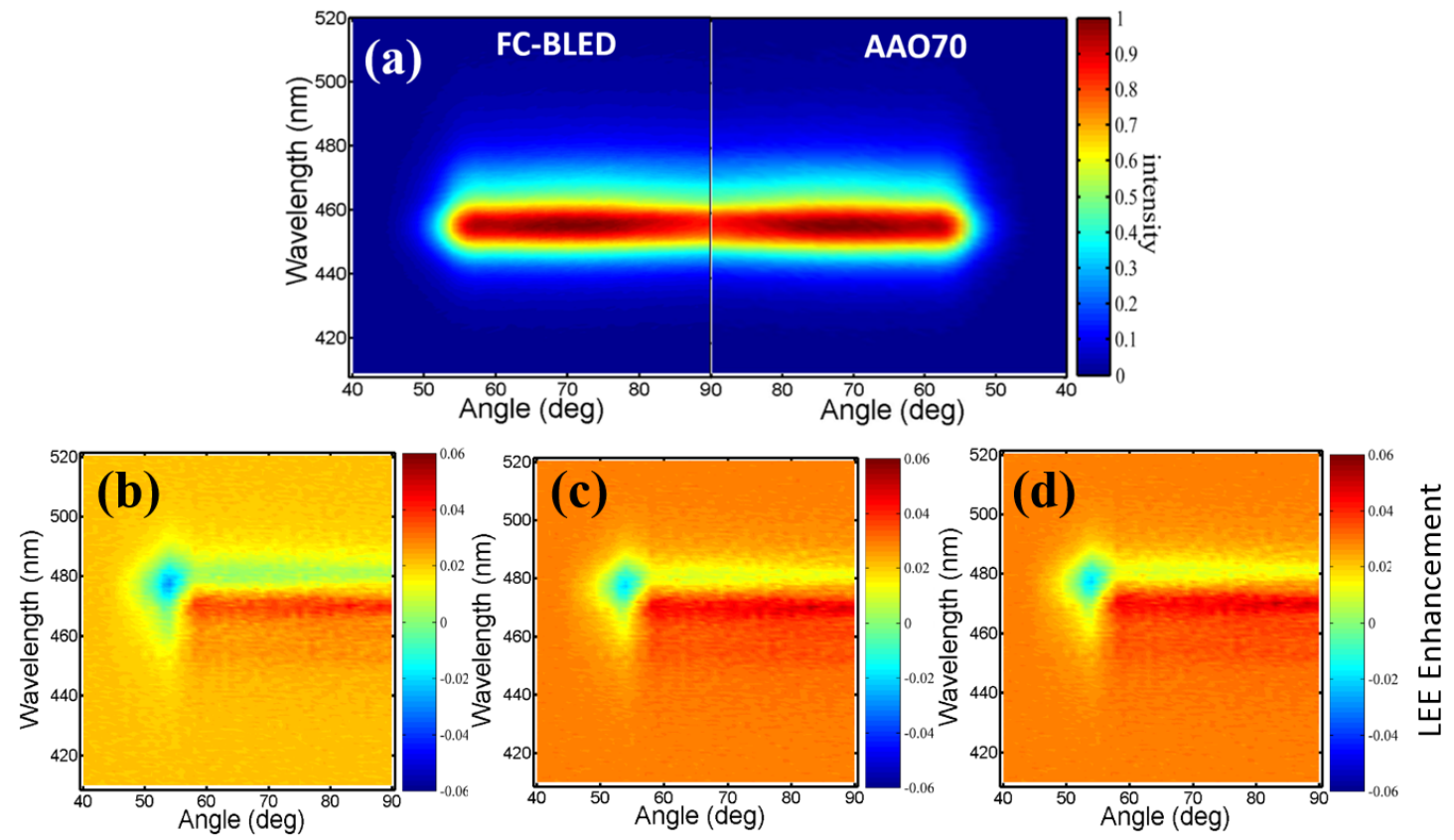

Figure 7: (a) Angle-resolved electroluminescence (AREL) spectra of samples FC-BLED and AAO70. Angular resolution of LEE enhancement of (b) AAO60, (c) AAO70, and (d) AAO80.

\begin{tabular}{|c|c|c|c|c|}
\hline Device & $\mathrm{LOP}(\mathrm{mW})$ at $350 \mathrm{~mA}$ & Emission peak (nm) & Radiation angle $\left({ }^{\circ}\right)$ & LEE enhancement (\%) \\
\hline Bare FC-BLEDs & $407.3 \pm 0.8$ & $453.8 \pm 0.1$ & $133.8 \pm 0.7$ & - \\
\hline Sample AAO60 & $416.2 \pm 5.0$ & $451.0 \pm 1.0$ & $134.4 \pm 0.3$ & 2.1 \\
\hline Sample AAO70 & $419.3 \pm 0.7$ & $450.4 \pm 0.5$ & $138.3 \pm 1.0$ & 2.9 \\
\hline Sample AAO80 & $414.0 \pm 1.0$ & $450.5 \pm 0.5$ & $137.6 \pm 0.5$ & 1.6 \\
\hline
\end{tabular}

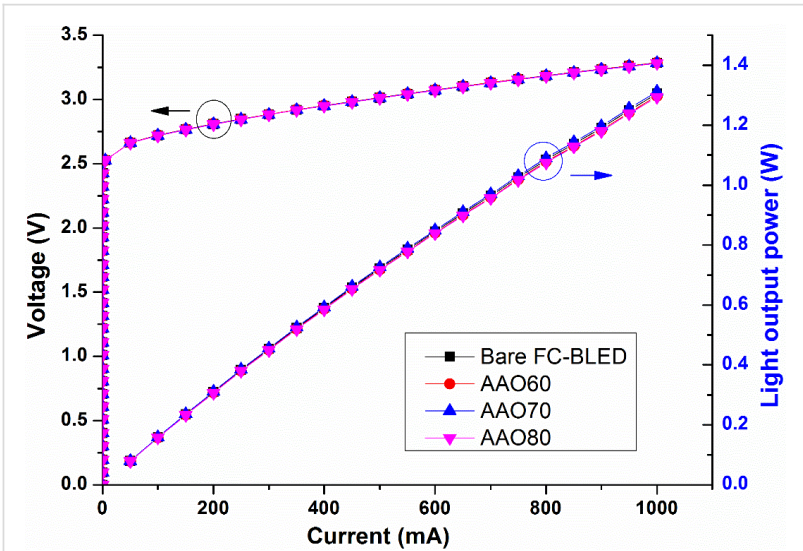

Figure 8: Typical light output power-current-voltage $(L-I-V)$ curves of the samples in this study.

\section{Rigorous coupled-wave analysis}

We used the rigorous coupled-wave analysis (RCWA) to verify our hypothesis and to clearly explain the reduction in total reflectivity and the existence of the surface plasmon wave in the samples. RCWA is a semianalytical method in computational electromagnetics that is typically applied to solve scattering from periodic dielectric structures [46]. Figure 9a shows the sample structure, which is constructed on the basis of SEM results, used in this calculation. Figure $9 \mathrm{~b}$ and Figure 9c show layers 1 and 2 as the calculation layers, respectively. Air hole diameters are set as the control parameters and are equal to the size of AAO60, AAO70, and AAO80. In Figure 9c, the diameter of $\mathrm{Al}_{2} \mathrm{O}_{3}$ is $100 \mathrm{~nm}$, which is consistent with the hole radius. If the hole radius decreases, then the yellow area (Al) will expand. Figure 10a shows the calculation results obtained with different $\mathrm{Al}_{2} \mathrm{O}_{3}$ thicknesses and diameter values of air holes in the absence of Al. All the three samples have the same transmittance of 440-450 nm. However, AAO80 has wider transmittance windows than other samples. Figure $10 \mathrm{~b}$ shows that transmittance drastically decreases when $\mathrm{Al}$ is present in the sample structure. The thickness of $\mathrm{Al}$ in the form of $\mathrm{Al}_{2} \mathrm{O}_{3}$ is less than $10 \mathrm{~nm}$. Figure 10c shows the modified absorption result for $\mathrm{Al}$ 


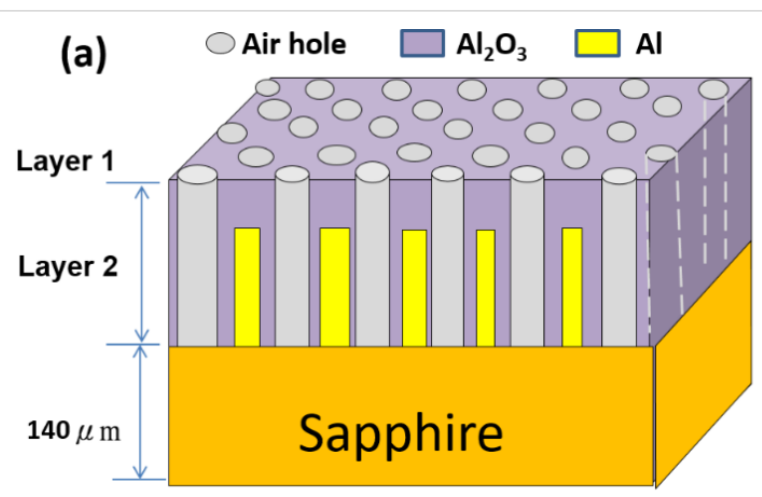

(b) Layer 1

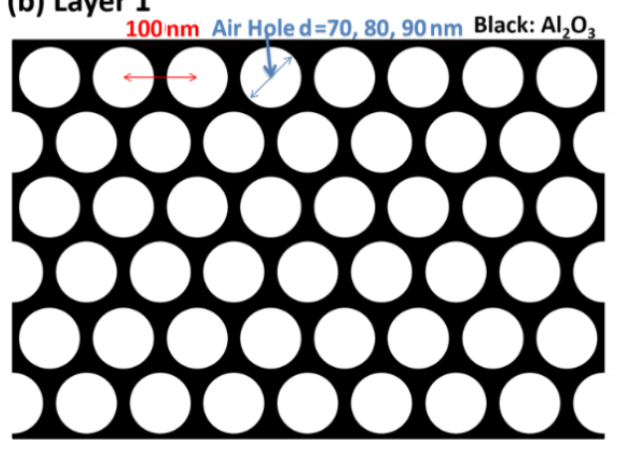

(c) Layer 2

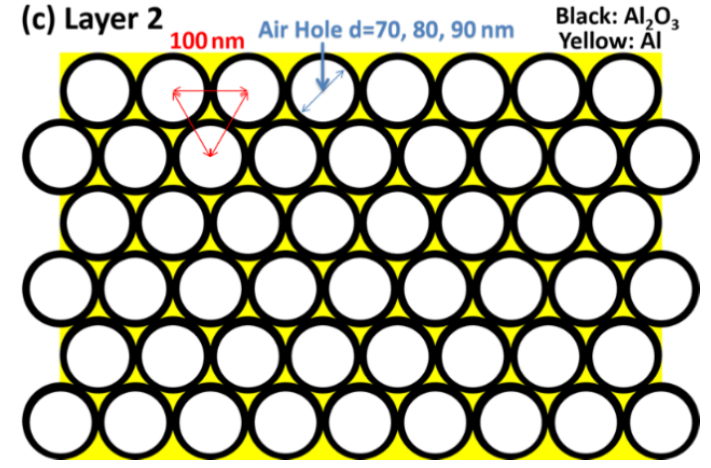

Figure 9: Sample structure used in rigorous coupled-wave analysis (RCWA) calculations: (a) AAO sample structure, (b) layer 1 structure and (c) layer 2 structure.
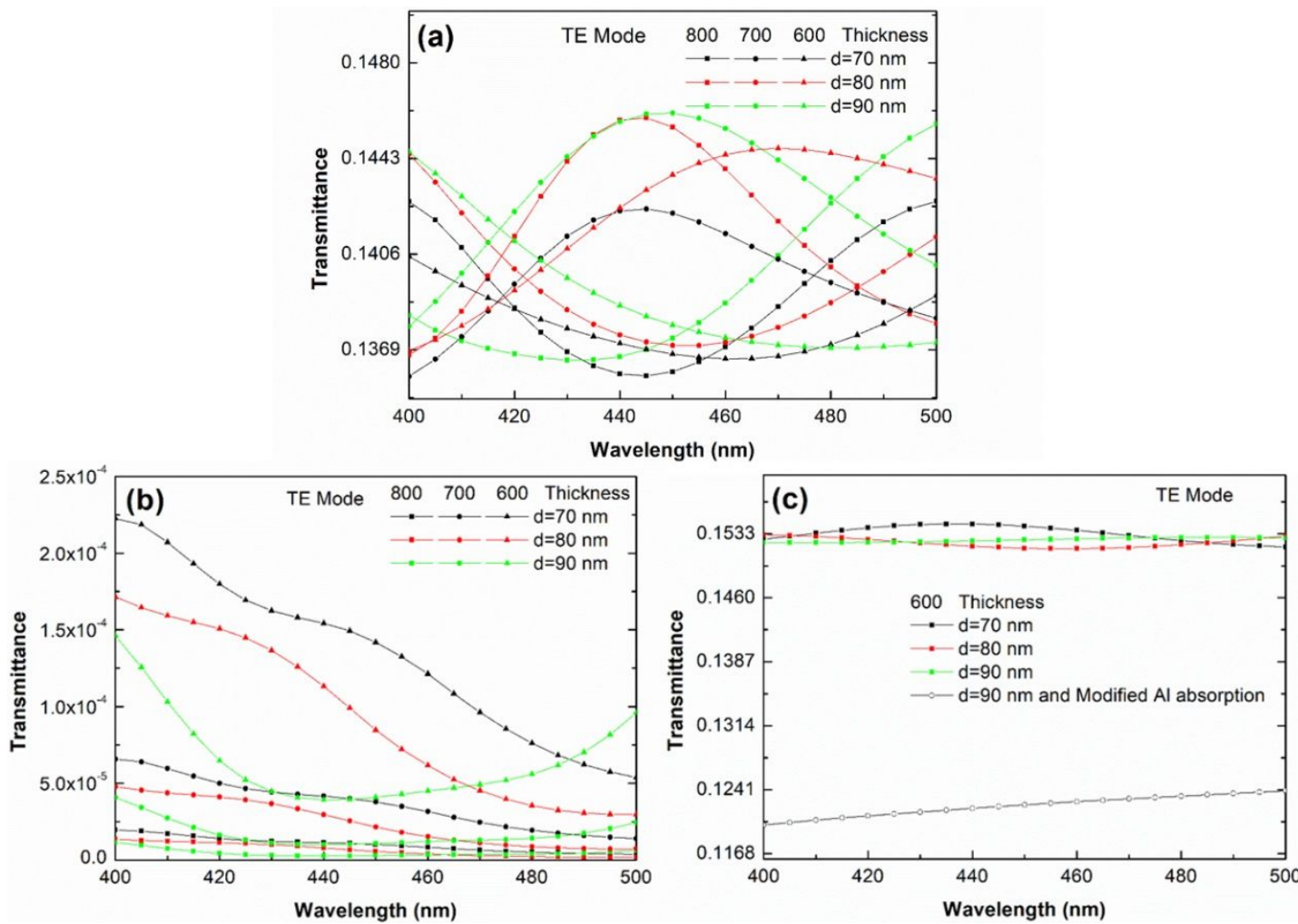

Figure 10: Rigorous coupled-wave analysis (RCWA) results obtained with different $\mathrm{Al}_{2} \mathrm{O}_{3}$ thickness and air-hole diameters (a) without $\mathrm{Al}$ (b) with $\mathrm{Al}$ and (c) with modified Al absorption. 
after the refractive index of the imaginary part (absorption) has been multiplied by 0.01 , that is, the artificial absorption of $\mathrm{Al}$ has decreased by 100 times. In this condition, the transmittance of the modified $\mathrm{Al}$ absorption is still lower than without $\mathrm{Al}$ calculations. This type of calculation result indicates reasonable physics. Extremely low transmittance exists when the thickness of $\mathrm{Al}$ is approximately $790-590 \mathrm{~nm}$. We redesigned the sample structure with different $\mathrm{Al}$ thicknesses in reference to the TEM results. We adjusted the thickness of $\mathrm{Al}_{2} \mathrm{O}_{3}$ as shown in Figure 11 to meet the different thickness values of AAO60, AAO70, and AAO8 as shown in Figure 11a, Figure 11b, and Figure 11c, respectively. Transmittance increases with decreasing $\mathrm{Al}$ thickness in the three samples. However, the transmittance of cases with low Al thickness is still less than that of cases without Al, as shown in Figure 10. These results show that the plasmonic effect contribution does not exist.

\section{Conclusion}

We produced AAO nanostructures on high-efficiency FC-BLEDs and found that various pore-widening durations can enhance LEE by approximately 1.6-2.9\%. Material analysis revealed that AAO structures are destroyed after the second pore widening process. Thus, LEE is not enhanced by insufficient or excessive pore-widening durations. The mechanism underlying the blue shift of the emission wavelength in the AAO structures of FC-BLEDs remains unclear. The AAO process enhances the LEE of LEDs by reducing the total light reflected by the surface roughness of LEDs. RCWA analysis indicated that surface plasmon waves are not involved in LEE enhancement.

\section{Experimental}

To produce a typical LED chip with a single-sided PSS, InGaN/ GaN MQW LEDs were grown on c-plane (0001)-oriented PSSs using a metal-organic chemical vapor deposition apparatus. An inductively coupled plasma etcher was used to prepare periodic arrays with a depth of $1.5 \mu \mathrm{m}$ on the PSS. Trimethylgallium, trimethylindium, ammonia, bicyclopentadienyl magnesium, and silane served as the precursors of $\mathrm{Ga}, \mathrm{In}, \mathrm{N}, \mathrm{Mg}$, and $\mathrm{Si}$, respectively. The epitaxial structure of the LEDs was grown in accordance with a previously published procedure [8]. The textured surface of the PSS occurred at the initial growth site of a GaN nucleation layer. A thick n-type GaN layer $(4 \mu \mathrm{m})$ doped with $\mathrm{Si}$, a ten-period $\mathrm{InGaN} / \mathrm{GaN}$ heterostructure used as the MQW, and a p-type $\mathrm{GaN}$ layer $(120 \mathrm{~nm})$ doped with $\mathrm{Mg}$ were vertically arranged on the nucleation layer in sequence. In the AAO process, a plate layer of aluminum film with a thickness of $2 \mu \mathrm{m}$ was coated onto the LED surface, and a $0.3 \mathrm{M}$ oxalic acid solu-
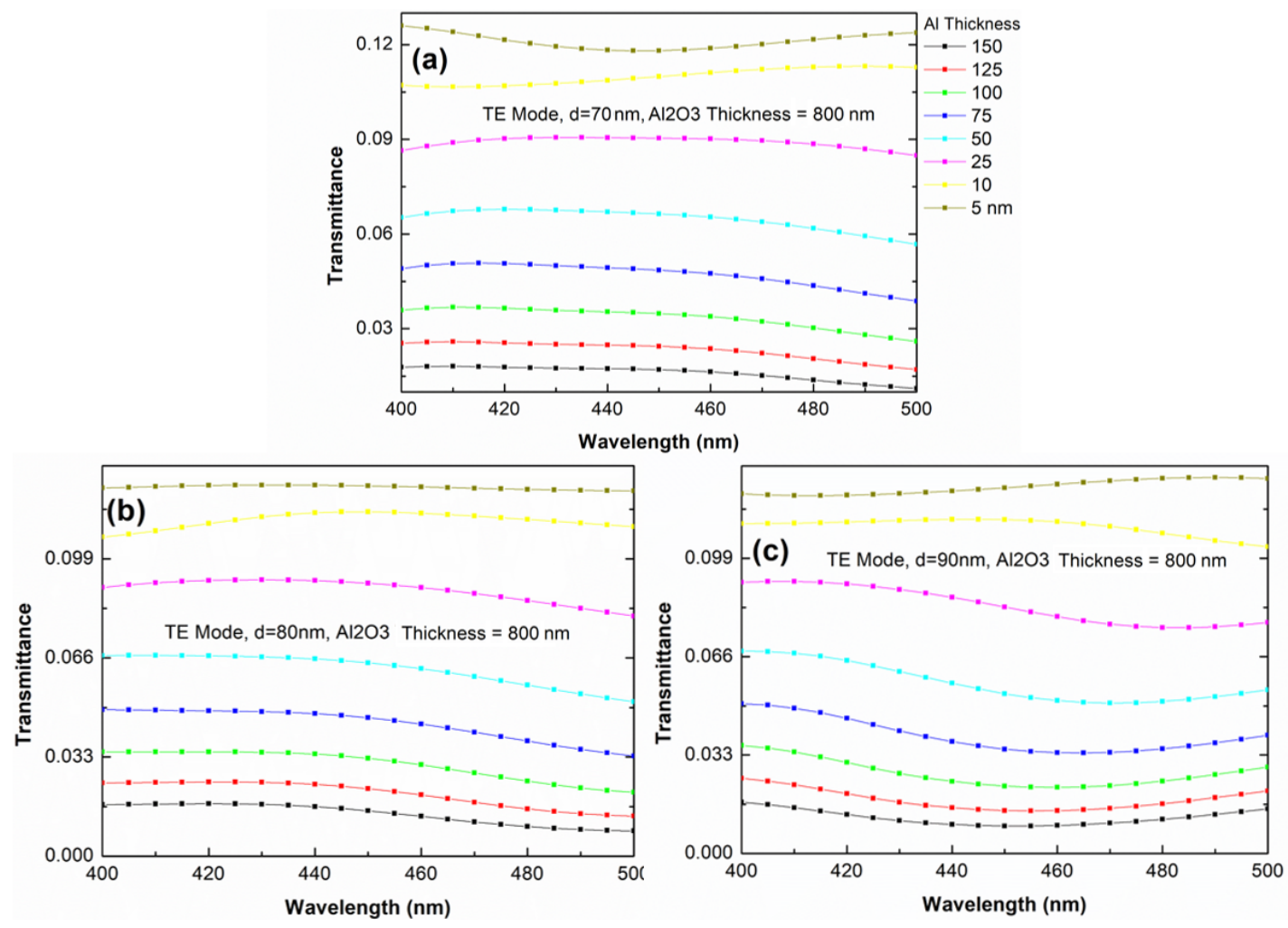

Figure 11: Rigorous coupled-wave analysis (RCWA) results with different $\mathrm{Al}$ thickness values and fixed $\mathrm{Al}_{2} \mathrm{O}_{3}$ thickness of $800 \mathrm{~nm}$ for samples (a) AAO60 (b) AAO70 and (c) AAO80 
tion was prepared. The LED was placed into the solution to act as the anode, and a platinum sheet was used as the cathode.

The electrolysis experiment was conducted under $40 \mathrm{~V}$ with an electrolysis time of $45 \mathrm{~min}$. Then, the system was placed in a mixed solution of $6 \mathrm{wt} \%$ phosphoric acid and $1.5 \mathrm{wt} \%$ chromic acid, and the first pore-widening process $(1 \mathrm{~h})$ and the second electrolysis process $(45 \mathrm{~min})$ were carried out. The second pore-widening process was conducted to eliminate possible residues in the barrier layer $\left(\mathrm{Al}_{2} \mathrm{O}_{3}\right)$ of the AAO [4749]. The second pore widening process was performed with durations of 60,70 , or $80 \mathrm{~min}$, and the resulting samples were denoted as AAO60, AAO70, and AAO80, respectively. The device structure is shown in Figure 12 after the AAO processes are completed.

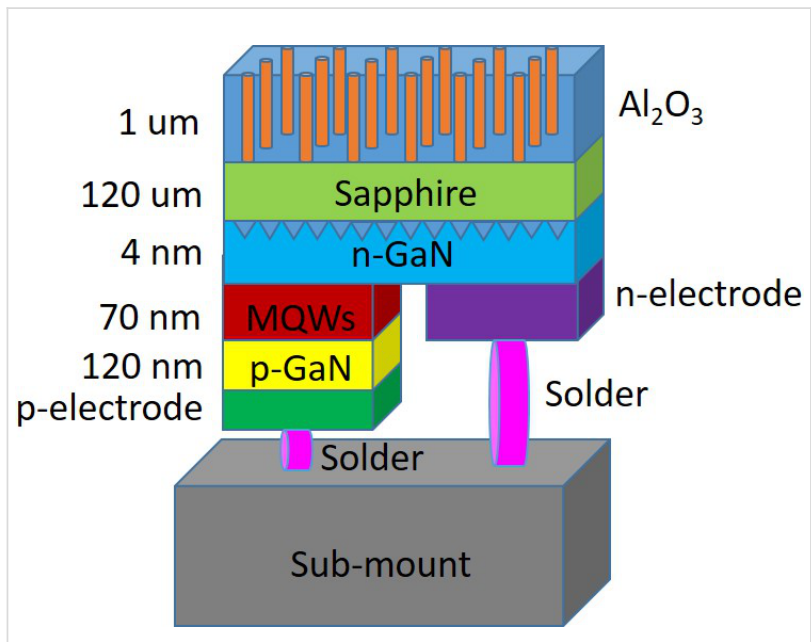

Figure 12: Structure of flip-chip LED with anodic aluminum oxide (AAO) processing.

\section{Acknowledgements}

This research was supported by the Ministry of Science and Technology, Republic of China, under grants MOST 104-2221-E-194-054, 105-2923-E-194-003-MY3, and 105-2112-M-194-005.

\section{ORCID ${ }^{\circledR}$ iDs}

Hsiang-Chen Wang - https://orcid.org/0000-0003-4107-2062

\section{References}

1. Schubert, E. F.; Kim, J. K. Science 2005, 308, 1274-1278. doi:10.1126/science.1108712

2. Taguchi, T.; Uchida, Y.; Kobashi, K. Phys. Status Solidi 2004, 201, 2730-2735. doi:10.1002/pssa.200405101

3. Okamoto, K.; Kawakami, Y. IEEE J. Sel. Top. Quantum Electron. 2009, 15, 1199-1209.

4. Pimputkar, S.; Speck, J. S.; DenBaars, S. P.; Nakamura, S. Nat. Photonics 2009, 3, 180-182. doi:10.1038/nphoton.2009.32
5. Grubor, J.; Lee, S. C. J.; Langer, K.-D.; Koonen, T.; Walewski, J. W. Wireless High-Speed Data Transmission with Phosphorescent White-Light LEDs. In Proceedings of the 2007 33rd European Conference and Exhibition of Optical Communication, Berlin, Germany, Sept 16-20, 2007; VDE Verlag GmbH: Berlin, Germany, 2008.

6. Chen, F.; Wang, K.; Qin, Z.; Wu, D.; Luo, X.; Liu, S. Opt. Express 2010, 18, 20926-20938. doi:10.1364/OE.18.020926

7. Lin, R. J.; sai, M.-S.; Sun, C.-C. Opt. Express 2015, 23, 16715-16722. doi:10.1364/OE.23.016715

8. Huang, K.-C.; Huang, Y.-R.; Tseng, C.-M.; Tseng, S.-H.; Huang, J.-E. Scr. Mater. 2015, 108, 40-43. doi:10.1016/j.scriptamat.2015.05.040

9. Vannahme, C.; Dufva, M.; Kristensen, A. Light: Sci. Appl. 2015, 4, 269. doi:10.1038/lsa.2015.42

10. Ryu, K. H.; Kim, H. Y.; Kim, S. K.; Lee, Y. J.; Min, S. H. Inorganic particle scattering film having a good light-extraction performance. U.S. Patent Application US20140234583A1, July 14, 2011.

11. Ding, Q.-a.; Li, K.; Kong, F.; Chen, X.; Zhao, J. J. Disp. Technol. 2014, 10, 909-916. doi:10.1109/JDT.2013.2281236

12. Shei, S.-C. IEEE J. Quantum Electron. 2014, 50, 629-632. doi:10.1109/JQE.2014.2329897

13. Li, X.-H.; Zhu, P.; Liu, G.; Zhang, J.; Song, R.; Ee, Y.-K.; Kumnorkaew, P.; Gilchris, J.-F.; Tansu, N. J. Disp. Technol. 2013, 9, 324-332. doi:10.1109/JDT.2013.2246541

14. Lee, C.-Y.; Huang, C.-C.; Lia, C.-L.; Chang, Y.-F.; Chen, S.-F.; Ho, C.-L.; Liu, J.-Z.; Wu, M.-C. IEEE Electron Device Lett. 2013, 34, 1283-1285. doi:10.1109/LED.2013.2278854

15. Ryu, S.-W.; Park, J.; Oh, J.-K.; Long, D. H.; Kwon, K.-W.; Kim, Y.-H.; Lee, J. K.; Kim, J. H. Adv. Funct. Mater. 2009, 19, 1650-1655. doi:10.1002/adfm.200801125

16. Cates, J. W.; Hayward, J. P.; Zhang, X. IEEE Trans. Nucl. Sci. 2013, 60, 1027-1032. doi:10.1109/TNS.2013.2249090

17. Jewell, J.; Simeonov, D.; Huang, S.-C.; Hu, Y.-L.; Nakamura, S.; Speck, J.; Weisbuch, C. Appl. Phys. Lett. 2012, 100, 171105. doi:10.1063/1.4705735

18. McGroddy, K.; Davida, A.; Matioli, E.; Iza, M.; Nakamura, S.; DenBaars, S.; Speck, J. S.; Weisbuch, C.; Hu, E. L. Appl. Phys. Lett. 2008, 93, 103502. doi:10.1063/1.2978068

19. Zhu, P.; Liu, G.; Zhang, J.; Tansu, N. J. Disp. Technol. 2013, 9, 317-323. doi:10.1109/JDT.2013.2250253

20. Zhu, P.; Tansu, N. Photonics Res. 2015, 3, 184. doi:10.1364/PRJ.3.000184

21. Zhu, P.; Tansu, N. Appl. Opt. 2015, 54, 6305-6312. doi:10.1364/AO.54.006305

22. Zhu, P.; Tan, C.-K.; Sun, W.; Tansu, N. Appl. Opt. 2015, 54, 10299-10303. doi:10.1364/AO.54.010299

23. Koo, W. H.; Youn, W.; Zhu, P.; Li, X.-H.; Tansu, N.; So, F. Adv. Funct. Mater. 2012, 22, 3454-3459. doi:10.1002/adfm.201200876

24. Zhu, P. Mater. Res. Express 2015, 2, 096202. doi:10.1088/2053-1591/2/9/096202

25. Zhu, P. J. Opt. (Bristol, U. K.) 2016, 18, 025403. doi:10.1088/2040-8978/18/2/025403

26. Jiang, S.; Feng, Y.; Chen, Z.; Zhang, L.; Jiang, X.; Jiao, Q.; Li, J.; Chen, Y.; Li, D.; Liu, L.; Yu, T.; Shen, B.; Zhang, G. Sci. Rep. 2016, 6, 21573. doi:10.1038/srep21573

27. Wang, X.; Han, G.-R. Microelectron. Eng. 2003, 66, 166-170. doi:10.1016/S0167-9317(03)00042-X

28. Kang, G.; Bae, K.; Nam, M.; Ko, D.-H.; Kim, K.; Padilla, W. J. Energy Environ. Sci. 2015, 8, 2650-2656. doi:10.1039/C5EE01757B 
29. Han, D.-S.; Kim, J.-Y.; Na, S.-I.; Kim, S.-H.; Lee, K.-D.; Kim, B.; Park, S.-J. IEEE Photonics Technol. Lett. 2006, 18, 1406-1408. doi:10.1109/LPT.2006.877565

30. Nakamura, S.; Mukai, T.; Senoh, M. Appl. Phys. Lett. 1994, 64, 1687-1689. doi:10.1063/1.111832

31. Wang, W.-K.; Wu, D.-S.; Lin, S.-H.; Huang, S.-Y.; Han, P.; Horng, R.-H. Jpn. J. Appl. Phys. 2006, 45, 3430-3432. doi:10.1155/2012/346915

32. Lee, J.-H.; Hwang, S.-M.; Kim, N.-S.; Lee, J.-H. IEEE Electron Device Lett. 2010, 31, 698-700. doi:10.1109/LED.2010.2048887

33. Cheng, B.-S.; Lee, C.-E.; Kuo, H.-C.; Lu, T.-C.; Wang, S.-C. Jpn. J. Appl. Phys. 2009, 48, 04C115. doi:10.1143/JJAP.48.04C115

34. Shen, C. F.; Chang, S. J.; Chen, W. S.; Ko, T. K.; Kuo, C. T.; Shei, S. C. IEEE Photonics Technol. Lett. 2007, 19, 780-782. doi:10.1109/LPT.2007.896574

35. Joo, D. H.; Lee, H. K.; Yu, J. S. IEEE Photonics Technol. Lett. 2012, 24, 1381-1383. doi:10.1109/LPT.2012.2204869

36. Baek, S.; Kang, G.; Shin, D.; Bae, K.; Kim, Y. H.; Kim, K. ACS Appl. Mater. Interfaces 2016, 8, 135-141. doi:10.1021/acsami.5b07783

37. Mattiucci, N.; D’Aguanno, G.; Everitt, H. O.; Foreman, J. V.; Callahan, J. M.; Buncick, M. C.; Bloemer, M. J. Opt. Express 2012, 20, 1868-1877. doi:10.1364/OE.20.001868

38. Hao, Q.; Wang, C.; Huang, H.; Li, W.; Du, D.; Han, D.; Qiu, T.; Chu, P. K. Sci. Rep. 2015, 5, 15288. doi:10.1038/srep15288

39. Okamoto, K.; Niki, I.; Shvartser, A.; Narukawa, Y.; Mukai, T.; Scherer, A. Nat. Mater. 2004, 3, 601-605. doi:10.1038/nmat1198

40. Kwon, M.-K.; Kim, J.-Y.; Kim, B.-H.; Park, I.-K.; Cho, C.-Y.; Byeon, C. C.; Park, S.-J. Adv. Mater. 2008, 20, 1253-1257. doi:10.1002/adma.200701130

41. Wang, H.-C.; Yu, X.-Y.; Chueh, Y.-L.; Malinauskas, T.; Jarasiunas, K.; Feng, S.-W. Opt. Express 2011, 19, 18893-18902. doi:10.1364/OE.19.018893

42. Kuo, Y.; Chang, W.-Y.; Lin, C.-H.; Yang, C.-C.; Kiang, Y.-W. Opt. Express 2015, 23, 30709-30720. doi:10.1364/OE.23.030709

43. Lin, C.-H.; Chen, C.-H.; Yao, Y.-F.; Su, C.-Y.; Shih, P.-Y.; Chen, H.-S.; Hsieh, C.; Kuo, Y.; Kiang, Y.-W.; Yang, C. C. Plasmonics 2015, 10 , 1029-1040. doi:10.1007/s11468-015-9902-9

44. Kuo, Y.; Su, C.-Y.; Hsieh, C.; Chang, W.-Y.; Huang, C.-A.; Kiang, Y.-W.; Yang, C. C. Opt. Lett. 2015, 40, 4229-4232. doi:10.1364/OL.40.004229

45. Kuo, Y.; Yao, Y.-F.; Chiu, M.-H.; Chang, W.-Y.; Yang, C. C.; Kiang, Y.-W. Plasmonics 2015, 10, 241-249. doi:10.1007/s11468-014-9801-5

46. Moharam, M. G.; Pommet, D. A.; Grann, E. B.; Gaylord, T. K. J. Opt. Soc. Am. A 1995, 12, 1077-1086. doi:10.1364/JOSAA.12.001077

47. Masuda, H.; Fukuda, K. Science 1995, 268, 1466-1468. doi:10.1126/science.268.5216.1466

48. Feiyue, L.; Zhang, L.; Metzger, R. M. Chem. Mater. 1998, 10, 2470-2480. doi:10.1021/cm980163a

49. Poinern, G. E. J.; Ali, N.; Fawcett, D. Materials 2011, 4, 487-527. doi:10.3390/ma4030487

\section{License and Terms}

This is an Open Access article under the terms of the Creative Commons Attribution License

(http://creativecommons.org/licenses/by/4.0), which permits unrestricted use, distribution, and reproduction in any medium, provided the original work is properly cited.

The license is subject to the Beilstein Journal of Nanotechnology terms and conditions: (https://www.beilstein-journals.org/bjnano)

The definitive version of this article is the electronic one which can be found at:

doi:10.3762/bjnano.9.152 